\title{
Design of Long-Term Sitting Effect Body Temperature Based on Microcontroller
}

\author{
A A Asril', M Irmansyah², E Madona ${ }^{3}$, A Nasution ${ }^{4}$ \\ Electro,PoliteknikNegeri Padang \\ Campus PoliteknikNegeri Padang LimauManis, Padang, West Sumatra, Indonesia ${ }^{1,2,3,4}$ \\ \{mirmansyah38@gmail.com¹, emadona38@gmail.com²\}
}

\begin{abstract}
Employeeshabits that working in offices are spend more than two-thirds of their working hours sitting in front of their desks and give little attention to good body position at work. This condition can cause health problems for themselves such as increasing the risk of hemorrhoids, heart disease, diabetes, obesity, and damage to joints, muscle, and posture. Sometimes the worker does not realize and never count how long they have been sitting. So, one of the efforts to avoid the risk of health problems caused by sitting too long is to make an instrument to warn the effect of long-term sitting with the temperature parameters. This system works based on the temperature detected on the designed seat bearing. The sensor used is SHT11 sensor, LED in bar graph design and buzzer as warning indicators if workers have been sitting too long. LED consists of three colors, which is green which means safe, yellow indicating a near to dangerous state, and red color meaning dangerous and workers are advised to stand for a while until the LED shows the green color. The results of testing show people who have a weight of approximately $70 \mathrm{KG}$ takes 172 minutes to pass the temperature of $37^{\circ} \mathrm{C}$, and people who have a weight of approximately $110 \mathrm{KG}$ takes 155 minutes to pass temperature $37^{\circ} \mathrm{C}$. Woman's body temperature faster increased by $0.31^{\circ} \mathrm{C}$ compared to males based on sitting time. Bargraph as an indicator showing green color when body temperature less than $36^{\circ} \mathrm{C}$, yellow bar graph active when body temperature is between $36^{\circ} \mathrm{C}$ to $37^{\circ} \mathrm{C}$, and red bar graph is active when temperature the body is more than $37^{\circ} \mathrm{C}$. The buzzer active if the body temperature has dangerous level when the temperature is above $37^{\circ} \mathrm{C}$.
\end{abstract}

Keywords: Warning Device, Buzzer, Sitting long, LED, SHT11. 


\section{Introduction}

In era of globalization, people are required to work faster to meet the needs of life. This situation creates routine activity in the long term. Employee's habits that working in the offices spend more than two-thirds of their working hours sitting in front of their desk and paying little attention to good body position at work. These habits can cause health problems for them. According to Mummery et al, long term sitting can increase the risk of hemorrhoid, heart disease, diabetes, obesity, and damage the joints, muscles and posture [1]-[3] The study also showed breaking down the sitting for two minutes every 20 minutes can improve the glucose and insulin response after meals, thereby reducing the risk of diabetes and heart disease[3]. But sometimes the employees are unaware and never count how long they have been sitting. Therefore it needs an instrument give a warning of how long a person has been sitting on his chair, so office workers, in particular, can avoid the risk of health problems caused by sitting too long.

The device is controlled using a microcontroller, utilizing a temperature sensor placed on the seat bearing to detect and measure the temperature on the seat bearing surface. The measured temperature is displayed on the LCD display and LED display. The using of this tool is expected to remind users how long they have been sitting to avoid the risk of health problems caused by sitting too long, especially for office workers. The same concept tool already available in 2016 made by Darma Inc. This tool is connected to the smartphone using Bluetooth communication and it costs quite an expensive \$ 200 also not sold in Indonesia[3]. There is not much research related to this topic, some research related to monitoring tools for health. Hartono Siswono in his research "Device for Helping The Blind"[4]. Yasunori.Tada "A smart shirt made with conductive ink and conductive foam for the measurement of electrocardiogram signals with unipolar precordial leads"[5]. A.Omairi "Low power wireless temperature and humidity sensing based on CM5000 node and SHT11 sensor [6]. K. Jaganmohan Reddy "Patient Temperature Monitoring System Using Bluetooth Communication" [7].

\section{Research Method}

\subsection{The Block Diagram}

This section describes the design of tools, system implementation and how system work in the outline of system design and followed by an explanation of the hardware consisting of several parts and software design tools.

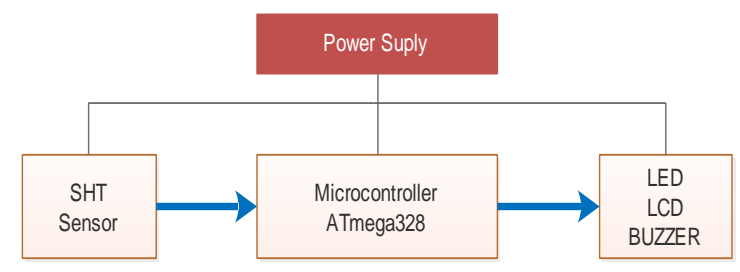

Figure 1. Block Diagram

This warning tool for long-term sitting risk works based on the temperature detected on the seat cushion. To detect the temperature this tool is equipped with SHT11 temperature sensor placed on the bottom seat cushion. The SHT11 sensor is a single-chip temperature and relative humidity sensor with multi-sensor module whose output has been digitally calibrated with a 5 
Volt voltage source and bi-directional 2-wire communication. This sensor system has 1 data path that is used for addressing commands and data readings.Data retrieval for each measurement is done by giving addressing command by microcontroller. Sensor serial pin data connected to the microcontroller gives addressing command on the SHT11 Data pin "00000101" to measure relative humidity and "00000011" for temperature measurement. SHT11 provides the data output of humidity and temperature on the data pin alternately in accordance with the clock provided by the microcontroller for the sensor to work. The SHT11 sensor has an ADC (Analog to Digital Converter) inside so the SHT11 data output is converted in digital data and does not require an external ADC in data processing on the microcontroller[8]. The SHT11 data retrieval scheme can be seen in figure 2 .

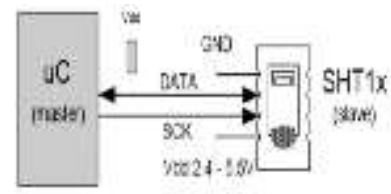

Figure 2. Scheme and Pin SHT 11

\begin{tabular}{ccccc}
\multicolumn{3}{c}{ Table 1. Pin SHT11 } \\
\hline \multicolumn{1}{c}{$\mathrm{Pi}$} & & Nam & Comment \\
\hline 1 & & GND & Ground \\
\hline 2 & & DAT & $\begin{array}{c}\text { Serial data } \\
\text { bidirectional }\end{array}$ \\
\hline & A & \multicolumn{2}{c}{$\begin{array}{c}\text { Serial clock } \\
\text { input }\end{array}$} \\
\hline 3 & & SCK & Supply 2.4 - \\
& & VDD & 5.5V \\
\hline 4 & & &
\end{tabular}

Microcontrolleratmega 328 controls the overall work of the system and inform of the value of seat cuisine temperature with an indicator of LED and display on LCD. LED and buzzers are warning indicators if workers have been sitting too long. LED is designed as bar graph and consists of three colors, green which means safe, yellow indicating a near-dangerous state, and red means dangerous and workers are advised to stand for a while until the LED shows the green color back. Buzzer indicates the detected temperature has reached the maximum limit. The LCD displays the temperature value detected by the SHT11 temperature sensor. Table 1 shows the working reference for the long-standing risk warning tool.

Table 2. Reference of warning devices of risk long-term sitting

\begin{tabular}{|c|c|c|c|}
\hline $\begin{array}{l}\text { Temperature } \\
\left({ }^{\mathrm{O}} \mathrm{C}\right)\end{array}$ & $\begin{array}{c}\text { Led } \\
\text { Indicator }\end{array}$ & $\begin{array}{c}\text { LCD } \\
\text { Display }\left({ }^{\circ} \mathrm{C}\right)\end{array}$ & Buzzer \\
\hline$<36$ & Green & Value of & Off \\
\hline $36-37$ & Yellow & temperature & Off \\
\hline$>37$ & Red & detection & On \\
\hline
\end{tabular}

Table 2 show if the temperature smaller than $36^{\circ} \mathrm{C}$, the LED indicator shows the green color and buzzer off, then the temperature sensor reading will continue to run and when the temperature sensor detects the temperature between $36^{\circ} \mathrm{C}$ to $37^{\circ} \mathrm{C}$ then LED Indicator will show yellow and buzzer still off, but if the temperature sensor detects the temperature greater than $37^{\circ} \mathrm{C}$ then the indicator LED will show the red and buzzer will be on. In this situation the worker is advised to stand for a while until the LED is green. Meanwhile the LCD will display the temperature detected by the SHT11 temperature sensor. The LCD is connected to pins 2, 3, 4, 
$5,6,7, \mathrm{VCC}$ and ground pins, and the buzzer connected to pin 8 on the microcontroller. This series uses trimpot as regulator of LCD display contras level.

\section{$2.2 \quad$ The physical design of the Device}

The design of hardware consists of the physical design of tools and circuit design. Tools made will be placed on the chairs and desks of office workers. The position of the SHT11 sensor on the seat bearing is shown in figure 3 .

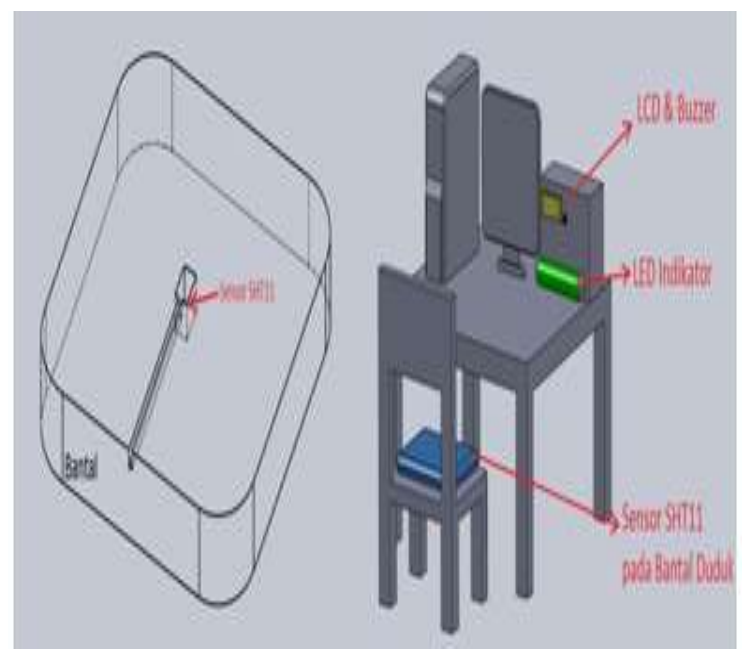

Figure 3. Sensor SHT11 position on the seat bearing

\subsection{The Electronic Circuits}

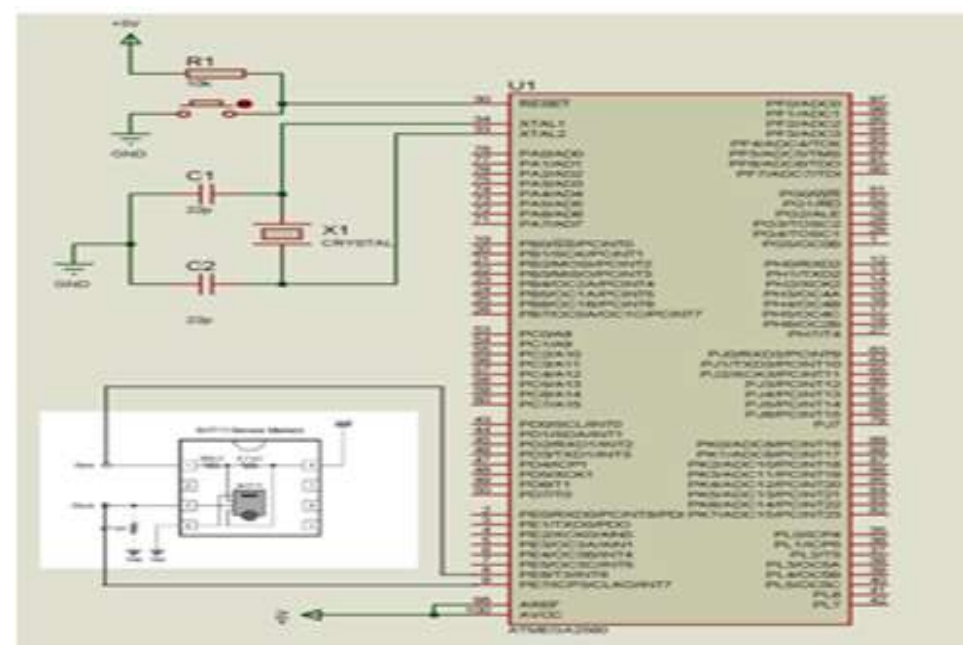



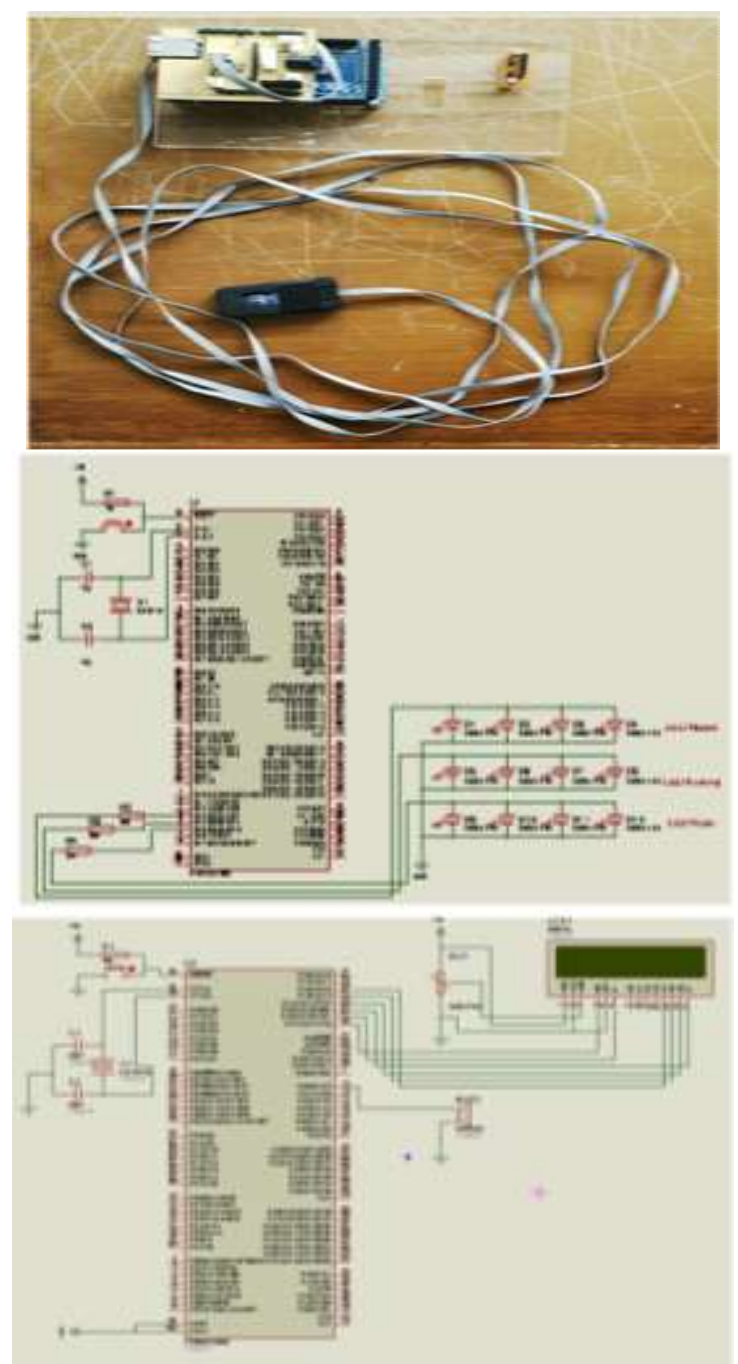

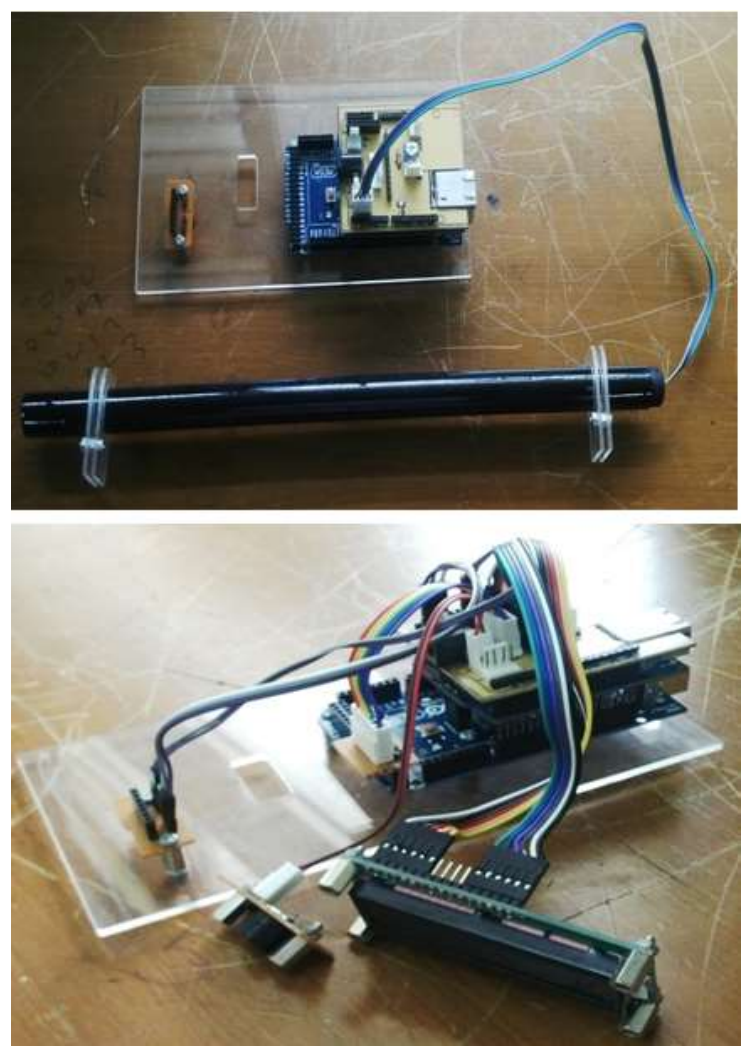

Figure 4. The Electronic Circuits Schematic

Figure 4 shows an electronic circuit of a device. The power supply circuit is used to supply power to microcontroller. This circuit uses 7805 regulator IC to generate the output voltage to the microcontroller of $5 \mathrm{~V}$. The SHT11 sensor is used to temperature detector. Pin 1 is connected to ground. Pin 2 is connected with pin 12. Pin 3 is connected with pin 13 and pin 4 is connected with VCC. The four pins are connected with the pin header that connects directly with the microcontroller.The LED circuit connected directly to 3 pins on the microcontroller, pins 9, 10, and 11. Each pin activates one type of color on the indicator LED display. Pin 9 consists of 4 green LEDs, pin 10 is connected with 4 yellow LEDs, and pin 11 is connected with 4 red LEDs. The LED indicator circuit has a 220 Ohm resistor on each pin connection.

\subsection{The Device Algoritma}

SHT sensor reads the body temperature of employees. The first condition, if the body temperature less than 36OC, the green led indicator connected to Pin 9 given the logic 'high' will on, the buzzer connected on pin 8 is logically 'low' will be off and the LCD connected to pin $(2,3,4,5,6,7)$ will display temperature data readable by SHT sensor.The second condition, if the body temperature equal to $36 \mathrm{OC}$ and $37 \mathrm{OC}$ then the yellow led indicator connected to Pin 10 given the logic 'high' will light up, the buzzer connected on pin 8 is logically 'low' will be off 
and the LCD connected to pin $(2,3,4,5,6,7)$ will display temperature data read by SHT sensor. The third condition, if the body temperature is equal to more than $37 \mathrm{OC}$ then the red led indicator connected to Pin 11 given the logic 'high' will light up, the buzzer connected on pin 8 is given the logic high will be ON and the LCD connected to pin $(2,3,4,5,6,7)$ will display temperature data read by SHT sensor.

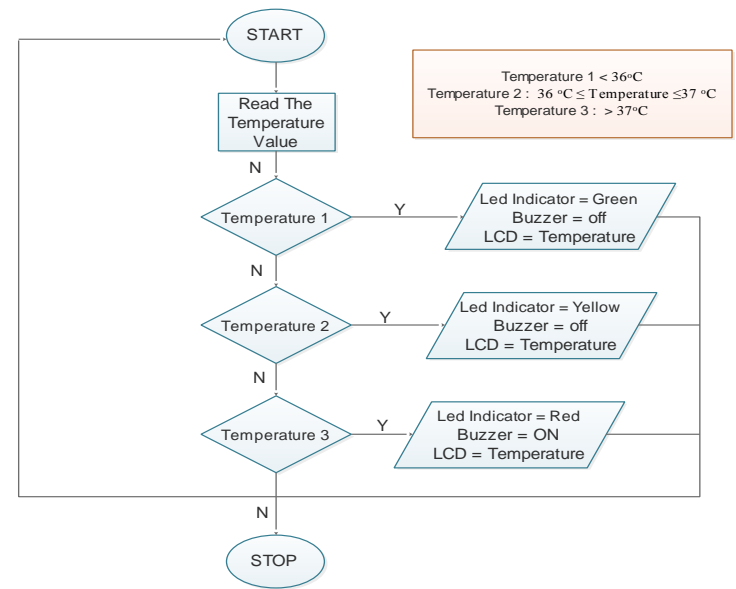

Figure 5. The Algorithms Flowchart

\section{Result And Analysis}

The overall testing tool aims to know the whole system functions as desired. This device is tested on six employees of State Polytechnic Padang. Figure 6 shows the testing of long-term sitting risk incomplete tools. The temperature measurement of the seat bearing to determine the increasing of employee body temperature is measured on the seat bearing based on the length of sitting while they work.Measurement of bearing temperature counted every half hour. The temperature measurement of the bearing is done in three stages. The first stage is the measurement of bearing temperature in two places that have different room temperatures but with the same bodyweight. The second stage of measurement is performed on two people with different weight but in a room with fixed room temperature. The third stage is comparing body temperature between men and women in length of sitting.

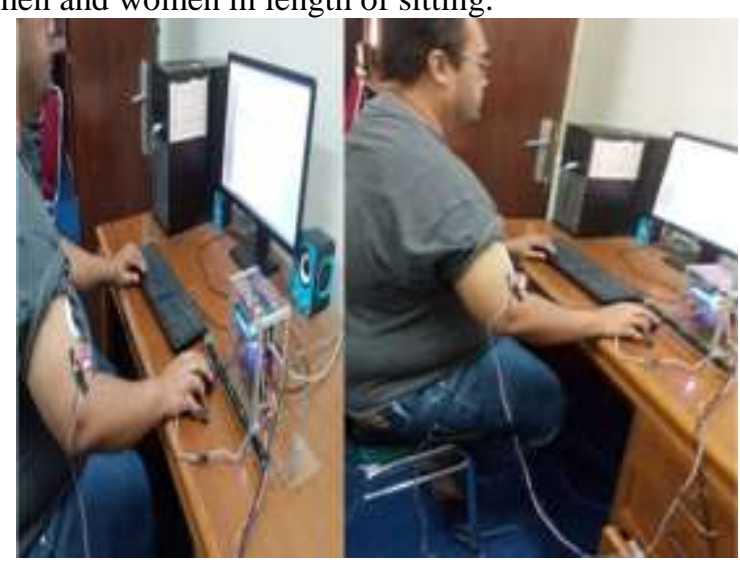




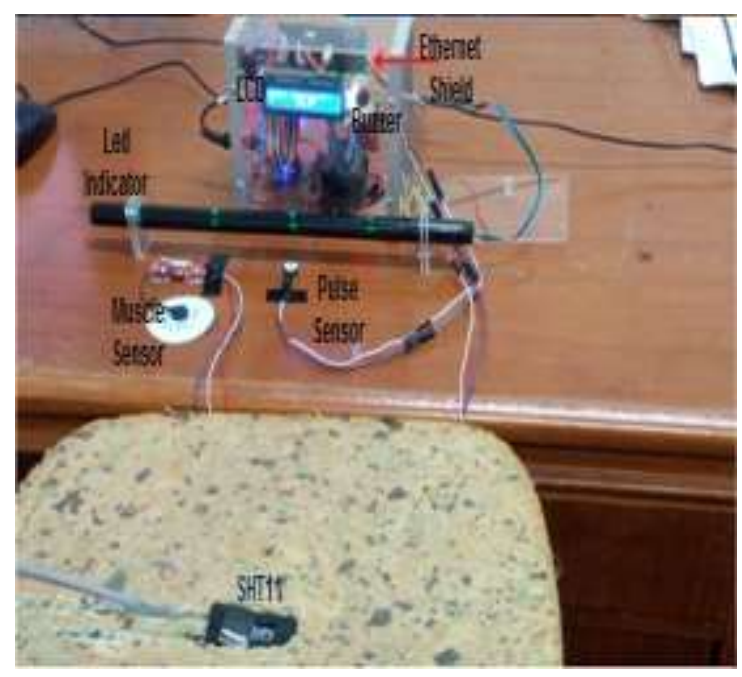

Figure 6. The testing of the monitoring system

Table 3. The experiment of warning system for effect of long-term sitting base on room temperature

\begin{tabular}{cccccccc}
\hline $\begin{array}{c}\text { Minute } \\
\mathrm{s}\end{array}$ & $\begin{array}{c}\text { Temperatur } \\
\mathrm{e}\left({ }^{\circ} \mathrm{C}\right)\end{array}$ & $\begin{array}{c}\text { Led } \\
\text { Indicato } \\
\mathrm{r}\end{array}$ & $\begin{array}{c}\text { Buzze } \\
\mathrm{r}\end{array}$ & $\begin{array}{c}\text { Minute } \\
\mathrm{s}\end{array}$ & $\begin{array}{c}\text { Temperatur } \\
\mathrm{e}\left({ }^{\circ} \mathrm{C}\right)\end{array}$ & $\begin{array}{c}\text { Led } \\
\text { Indicato } \\
\mathrm{r}\end{array}$ & $\begin{array}{c}\text { Buzze } \\
\mathrm{r}\end{array}$ \\
\hline 1 & 31.12 & Green & Off & 1 & 28.96 & Green & Off \\
\hline 30 & 34.61 & Green & Off & 30 & 34.51 & Green & Off \\
\hline 60 & 35.21 & Green & Off & 60 & 35.56 & Green & Off \\
\hline 90 & 35.72 & Green & Off & 90 & 36.21 & Yellow & Off \\
\hline 120 & 36.12 & Yellow & Off & 120 & 36.53 & Yellow & Off \\
\hline 150 & 36.57 & Yellow & Off & 150 & 36.88 & Yellow & Off \\
\hline 180 & 36.91 & Yellow & Off & 172 & 37.03 & Red & On \\
\hline 195 & 37.02 & Red & On & 180 & 37.05 & Red & On \\
\hline
\end{tabular}

Table 3 shows the temperature of the room very influences the temperature of the bearing at the beginning of the measurement. In the early minute's sensor SHT11 detects temperature bearing approaching room temperature. Further measurements were performed by two people with different weights but in the same room and room temperature remained $27^{\circ} \mathrm{C}$. Measurements were twice with the first weight $70 \mathrm{KG}$ and the second weight $110 \mathrm{KG}$. The test results can be seen in table 4 .

The result show monitoring body temperature of two people with bodyweight $70 \mathrm{KG}$ and $110 \mathrm{KG}$ can seethe body weight influence the speed of body temperature rise which measured on the bearing. In the first weight $70 \mathrm{KG}$ reaches body temperature above $37^{\circ} \mathrm{C}$ in 172 minutes, while the second person weight $110 \mathrm{KG}$ reaches body temperature above $37^{\circ} \mathrm{C}$ in 155 minutes. This indicates more weight of body so the body temperature increases faster which measures in the pillow reaches temperatures over $37^{\circ} \mathrm{C}$. Temperature greater than $37{ }^{\circ} \mathrm{C}$ is categorized 
exceeding above normal human body temperature. In the third stage, compare the body temperature measurement by long-term sitting male with female. The measurement results can be seen in table 5 .

Table 4. The experiment of warning system for effect of long-term sitting base on weight

\begin{tabular}{cccccccc}
\hline $\begin{array}{c}\text { Minute } \\
\mathrm{s}\end{array}$ & $\begin{array}{c}\text { Temperatur } \\
\mathrm{e}\left({ }^{\mathrm{O}} \mathrm{C}\right)\end{array}$ & $\begin{array}{c}\text { Led } \\
\text { Indicato } \\
\mathrm{r}\end{array}$ & $\begin{array}{c}\text { Buzze } \\
\mathrm{r}\end{array}$ & $\begin{array}{c}\text { Minute } \\
\mathrm{s}\end{array}$ & $\begin{array}{c}\text { Temperatur } \\
\mathrm{e}\left({ }^{\mathrm{O}} \mathrm{C}\right)\end{array}$ & $\begin{array}{c}\text { Led } \\
\text { Indicato } \\
\mathrm{r}\end{array}$ & $\begin{array}{c}\text { Buzze } \\
\mathrm{r}\end{array}$ \\
\hline 1 & 28.96 & Green & Off & 1 & 28.01 & Green & Off \\
\hline 30 & 34.51 & Green & Off & 30 & 32.52 & Green & Off \\
\hline 60 & 35.56 & Green & Off & 60 & 34.58 & Green & Off \\
\hline 90 & 36.21 & Yellow & Off & 90 & 35.86 & Green & Off \\
\hline 120 & 36.53 & Yellow & Off & 120 & 36.36 & Yellow & Off \\
\hline 150 & 36.88 & Yellow & Off & 150 & 36.98 & Yellow & Off \\
\hline 172 & 37.03 & Red & On & 155 & 37.02 & Red & On \\
\hline 180 & 37.05 & Red & On & 165 & 37.08 & Red & On \\
\hline
\end{tabular}

Table 5. The experiment of warning system for effect of long-term sitting base on different $\operatorname{sex}$

\begin{tabular}{|c|c|c|c|c|c|c|c|c|c|}
\hline \multicolumn{5}{|c|}{ Man } & \multicolumn{5}{|c|}{ Woman } \\
\hline \multirow[t]{2}{*}{ Minute } & \multicolumn{4}{|c|}{ Temperature $\left({ }^{\mathrm{O}} \mathrm{C}\right)$} & \multirow[t]{2}{*}{ Minute } & \multicolumn{4}{|c|}{ Temperature $\left({ }^{\mathrm{O}} \mathrm{C}\right)$} \\
\hline & $\begin{array}{c}\text { Rizky } \\
(58 \\
\mathrm{KG}) \\
\end{array}$ & $\begin{array}{c}\text { Jaka } \\
(59 \\
\mathrm{KG}) \\
\end{array}$ & $\begin{array}{c}\text { Hanafi } \\
(58 \\
\mathrm{KG}) \\
\end{array}$ & Average & & $\begin{array}{c}\text { Nela } \\
(61 \\
\text { KG) }\end{array}$ & $\begin{array}{l}\text { Ani } \\
(62 \\
K G)\end{array}$ & $\begin{array}{c}\text { Citra } \\
(62 \\
\mathrm{KG})\end{array}$ & Average \\
\hline 1 & 29.04 & 29.52 & 29.22 & 29.26 & 1 & 29.75 & 30.12 & 30.07 & 29.98 \\
\hline 30 & 33.90 & 33.38 & 33.51 & 33.59 & 30 & 34.38 & 34.55 & 34.10 & 34.34 \\
\hline 60 & 34.88 & 34.76 & 34.79 & 34.81 & 60 & 35.11 & 35.21 & 35.05 & 35.12 \\
\hline
\end{tabular}

Measurement according to sex differences performed at 6 people, consist of 3 men and 3 women have almost the same weight which ranges from $58 \mathrm{KG}$ to $62 \mathrm{KG}$ and average weight is $60 \mathrm{KG}$. The measurement results in Table 5 show the men sit down for sixty-minute the measured body temperature average is $34,81^{\circ} \mathrm{C}$, while the women sit for sixty-minute measured body temperature average is $35,12^{\circ} \mathrm{C}$. This shows that the female body temperature rises faster than the male body temperature of $0,31^{\circ} \mathrm{C}$

\section{Conclusions}

This paper presents the design of the warning tool for long term sitting effect with temperature parameters. The design of the tool is tested to the employees in the State Polytechnic of Padang to know the function of the monitoring tool. Based on the results of testing the tool is known people have a weight approximately $70 \mathrm{KG}$ takes 172 minutes to pass the temperature $37^{\circ} \mathrm{C}$ and people have a weight of approximately $110 \mathrm{KG}$ takes 155 minutes to pass temperature $37^{\circ} \mathrm{C}$. Woman's body temperature increased faster by $0,31^{\circ} \mathrm{C}$ compared to male body temperature based on sitting time. Bargraph indicator will green when body temperature less than $36^{\circ} \mathrm{C}$, yellow when body temperature between $37^{\circ} \mathrm{C}$ to $37^{\circ} \mathrm{C}$ and red if body temperature larger than $37^{\circ} \mathrm{C}$. Buzzer as an active indicator when the body temperature has danger conditions when the temperature more than $37^{\circ} \mathrm{C}$. 


\section{References}

[1] W. K. Mummery, G. M. Schofield, R. Steele, E. G. Eakin, and W. J. Brown, "Occupational sitting time and overweight and obesity in Australian workers," Am. J. Prev. Med., vol. 29, no. 2, pp. 91-97, 2005.

[2] B. M. Lynch and N. Owen, "Too much sitting and chronic disease risk: steps to move the science forward," Ann. Intern. Med., vol. 162, no. 2, pp. 146-147, 2015.

[3] A. A. Thorp et al., "Deleterious associations of sitting time and television viewing time with cardiometabolic risk biomarkers: Australian Diabetes, Obesity and Lifestyle (AusDiab) study 2004-2005," Diabetes Care, vol. 33, no. 2, pp. 327-334, 2010.

[4] H. Siswono and A. Wicaksono, "Device for Helping The Blind," Int. J. Electr. Eng. Informatics, vol. 9, no. 2, p. 313, 2017.

[5] Y. Tada, Y. Amano, T. Sato, S. Saito, and M. Inoue, "A smart shirt made with conductive ink and conductive foam for the measurement of electrocardiogram signals with unipolar precordial leads," Fibers, vol. 3, no. 4, pp. 463-477, 2015.

[6] A. Omairi and Z. H. Ismail, "Low power wireless temperature and humidity sensing based on CM5000 node and SHT11 sensor," in 2016 IEEE International Conference on Underwater System Technology: Theory and Applications (USYS), 2016, pp. 183-187.

[7] K. J. Reddy and B. S. Kumar, "Patient Temperature Monitoring System Using Bluetooth Communication," Int. J. Eng. Trends Technol., vol. 16, no. 4, 2014.

[8] "Sensirion Humidity SHT11 Datasheet," Sensor the companity, 2015. 